\title{
El documental y el noir: hibridación a través del cine de género ficcional
}

\author{
Documentary and noir: \\ hybridization through fictional genre cinema
}

https://doi.org/10.22235/d33.2374

\author{
Pablo Lanza \\ ORCID: 0000-0002-8131-4225
}

Universidad de Buenos Aires, Argentina.

\section{RESUMEN}

Este artículo se propone trabajar sobre el problema de la hibridación en el cine documental. Habitualmente considerado un rasgo del cine contemporáneo, el objetivo es efectuar un repaso de corte diacrónico para revisar esta hipótesis; para ello se hará foco en el intercambio del género policial con el documental en dos momentos distintos de la filmografía argentina: la década del cincuenta, con el ciclo ficcional de policiales Ilamadas "semidocumentales", y dos documentales contemporáneos que dialogan con el estilo del film noir. Para el análisis se repasan conceptos como híbrido y género, y se consideran las particularidades del estilo documental en ambos períodos, donde se puede observar el paso de un estilo impersonal a los relatos en primera persona.

Palabras clave: documental; hibridación; documental de investigación; primera persona; film noir.

\begin{abstract}
TThis article aims to work on the problem of hybridization in documentary film. Usually considered a feature of contemporary cinema, the objective is to carry out a diachronic review to revise this hypothesis; to do so, the focus will be on the exchange between the police genre and the documentary in two different moments of Argentine filmography: the fifties, with the fictional cycle of police officers called "semidocumentaries", and two contemporary documentaries that dialogue with the style of film noir. For the analysis, concepts such as hybrid and genre are reviewed, and the particularities of the documentary style in both periods are considered, where the passage from an impersonal style to first-person accounts can be observed.
\end{abstract}

Keywords: documentary; hybridization; investigative documentary; first person; film noir. 


\section{Introducción}

A comienzos del nuevo siglo la cinematografía documental atravesó uno de los momentos de mayor visibilidad de su larga historia, que se tradujo, por ejemplo, en una importante presencia en festivales cinematográficos. Entre los motivos que la crítica especializada esgrimió para explicar esta situación fue que el cine de lo real había expandido sus límites estilísticos y temáticos, enumerando entre otras estrategias el giro subjetivo que se produjo con la incorporación de la primera persona y de ciertas "mezclas" con la ficción que resultaban novedosas. En este marco varios autores han propuesto hablar de una era postdocumental:

un complejo panorama audiovisual donde las distinciones genéricas son más que problemáticas, donde el aspecto documental y lo documental se expanden a otros discursos audiovisuales, donde la subjetividad y el humor han dejado de ser un anatema, y donde el grado de actuación y manipulación inherente a toda representación audiovisual de lo real no resulta tan problemática para la audiencia (Oroz y de Pedro Amatria, 2009, p. 23).

Justamente una de las modalidades que permitiría dar cuenta de esta mixtura del documental es la adopción de elementos del cine de género ficcional, a la que se caracterizó como "hibridación genérica". En América Latina esta modalidad ha sido explorada recurriendo a géneros como el melodrama en Peões (2004), de Eduardo Coutinho, y Um passaporte húngaro (2003), de Sandra Kogut; la road movie en filmes como Return to Bolivia (2008), de Mariano Raffo, y The illusion (2008), de Susana Barriga e incluso recientemente el cine de terror en Ataque de pánico (2017), de Ernesto Ardito, entre otros.

En este sentido, nos interesa abordar el documental con ciertos tintes del film noir, o lo que podriamos llamar documental noir; un estilo que ha cobrado impulso en los últimos años tanto en el cine como la televisión mediante diversas combinaciones. ${ }^{1}$ Si bien pueden hallarse ejemplos en una escala global, nos centraremos en este trabajo en dos documentales argentinos que poseen varios rasgos comunes: Yo no sé qué me han hecho tus ojos (2003), de Sergio Wolf y Lorena Muñoz, y El rascacielos latino (2012), de Sebastián Schindel. ${ }^{2}$ Antes nos detendremos en los policiales llamados "semidocumentales" de la década del cincuenta, un ciclo de filmes que ensayó un diálogo entre ambas formas en el pasado con el objetivo de poner en tela de juicio la noción de la hibridación como un rasgo exclusivamente contemporáneo y observar así el diálogo bidireccional entre ficción y documental.

El análisis se centrará en la utilización de la narración over y off como herramienta compartida por las poéticas documentales y el film noir; el uso de la entrevista como medio de investigación; los aspectos performativos que se manifiestan en la utilización de aspectos iconográficos del detective en el policial; y la adopción de la primera persona como motivo narrativo.

\section{La hibridación en el cine}

Desde hace unas décadas la idea de hibridación en el cine, y en particular en el documental, ha sido resaltada por el discurso crítico. A modo de ejemplo, al referirse al documental estadounidense de fines de la década del ochenta, Paul Arthur se refería a "un grado de hibridación sin precedentes" (1993, p. 127) para caracterizar a filmes como Sherman's

$1:$ : Esto resulta especialmente cierto en los documentales televisivos sobre crimenes que han cobrado popularidad en las plataformas de streaming como Making of a murderer (2015-2018) o The Staircase (2004-2018).

2:: Entre muchos títulos que pueden ubicarse dentro de esta variante se pueden nombrar los siguientes: $M$ (2007) de Nicolás Prividera, Imagen final (2008) de Andrés Habegger, Malka, una chica de la Zwi Migdal (2014) de Walter Tejblum, Agosto final (2016) de Eduardo Sánchez y el falso documental Los corroboradores (2018) de Luis Bernárdez. Este artículo se centra en Yo no sé qué me han hecho tus ojos y El rascacielos latino, por considerarlos los que con mayor consistencia ensayan el cruce documental y noir. 
March (1985), de Ross McElwee, y The Thin Blue Line (1988), de Errol Morris, este último justamente uno de los antecedentes del estilo que trabajamos en este artículo. Es decir, que hace ya muchos años que se subraya esta característica para caracterizar el presente más anárquico del cine de no ficción y discutir la caracterización del documental como un ejemplo de "discurso sobrio", recuperando la propuesta del ubicuo trabajo de Bill Nichols (1997).

Ahora bien, ¿qué se comprende por el término "híbrido"? Como señalara Janet Staiger (1997), la noción de hibridez proviene de la zoología y la botánica para describir a la cruza de distintas especies. Uno de los primeros autores en aplicarlo en el campo de las disciplinas humanistas fue el lingüista ruso Mijail Bajtín en la década del treinta:

[Se denomina] construcción híbrida al enunciado que, de acuerdo con sus características gramaticales (sintácticas) y compositivas, pertenece a un solo hablante; pero en el cual, en realidad, se mezclan dos enunciados, dos maneras de hablar, dos estilos, dos "lenguas», dos perspectivas semánticas y axiológicas (Bajtín, 1989, pp. 121-122).

Bajtín postuló al híbrido novelesco como "un sistema de combinaciones de lenguajes organizado desde el punto de vista artístico; un sistema que tiene como objetivo iluminar un lenguaje con la ayuda de otro lenguaje" (1989, p. 177). Es decir que la metáfora de la hibridez, tal como la entiende Bajtín, apunta al diálogo intercultural, a la mezcla de dos lenguajes distintos en aras de producir un intercambio.

Desde la concepción bajtiniana la hibridez no se daría con la mera mixtura de géneros ficcionales. Recuperando a Staiger una vez más, resulta necesario señalar que los géneros nunca funcionaron de manera pura ni siquiera durante el período industrial clásico en Hollywood, por lo que la autora propone referirse a esta mezcla de elementos de géneros como "endogamia" (1997). No obstante, si consideramos que documental y ficción han buscado diferenciarse por diversos motivos a lo largo de sus respectivas historias, la mixtura de elementos de ambos discursos habilita el uso del término hibridación de una manera que no resulta tan compleja.

Autores más contemporáneos como David Duff han continuado con esta concepción, según la cual la hibridación se define como "el proceso mediante el cual dos o más géneros se combinan para formar uno nuevo o un subgénero, o por el cual elementos de dos o más géneros se combinan en una obra" (2000, p. 14) pero la han caracterizado como un rasgo típicamente posmoderno. Si bien el documental se presentó como una antinomia de la ficción, un paliativo frente a los pecados del cine ficcional -la filmación en estudios, la herencia literaria, el uso de actores- sus realizadores y pensadores nunca negaron que "el tratamiento creativo de la realidad" podía acudir a estructuras narrativas, construcciones de personajes y puesta en escena similares a las del filme de ficción. Todo esto permite pensar que la hibridación no es un rasgo exclusivo del cine posmoderno (Bernini, 2012), sino que ha operado en diversos momentos de su historia de manera bidireccional. Sobre este aspecto nos detendremos a continuación considerando los intercambios entre el policial y el cine documental durante el período clásico-industrial del cine argentino y su intertexto con el cine estadounidense.

Ficciones híbridas en el período clásico-industrial argentino: el policial "semidocumental"

El cine negro estadounidense o film noir se desarrolló principalmente durante los años cuarenta y cincuenta, y fue agrupado bajo tal etiqueta de forma posterior gracias a los esfuerzos de la crítica francesa. El noir se caracterizó por una mezcla de diversas influencias -la literatura pulp de autores como Raymond Chandler y James Cain, un uso "no tradicional" de la fotografía basada en la "oposición de áreas de luz y oscuridad” (Place y Peterson, 1974, p. 67) que ha sido emparentada al expresionismo alemán (Esquenazi, 2018; Broe, 2014; Spicer, 2002; Naremore, 1998)- y suele ser interpretado como un reflejo del descontento y nihilismo que el conflicto bélico generó en la sociedad estadounidense en esos años. 
$\mathrm{Al}$ no haber sido concebido como un género de forma estándar desde la esfera de la producción, el film noir como objeto se caracterizó por múltiples variantes. Es posible argumentar que la principal de ellas se ocupa de investigadores privados y crímenes pasionales orquestados por mujeres fuertes (las femme fatale) y hombres débiles. No obstante, la historia del cine negro suele dividirse en múltiples ciclos. En su influyente artículo sobre el estilo noir, el crítico y realizador cinematográfico Paul Schrader argumentó que este no constituía un género ya que "no está definido, como lo están los géneros del western y de gángsters, por convenciones de escenario y conflicto, sino más bien por las más sutiles cualidades de tono y atmósfera" (2008, p. 307).

Schrader esboza una periodización del cine negro en tres fases: el período bélico centrado en relatos de detectives y "lobos solitarios" entre 1941 y 1946, el realismo de posguerra centrado en "el crimen en las calles, la corrupción política y la rutina policial" comprendido entre los años 1945-1949, y el "período de la acción psicótica y el impulso suicida” desde 1949 a 1953 (2008, p. 314). En la segunda de estas fases, ubicada hacia fines de la década del cuarenta, el cine negro se entronca con el documental para acentuar el realismo de sus narrativas. Esta particular variante, denominada en su época "semidocumental" o ciclo "policiaco documental" en estudios posteriores (Heredero y Santamarina, 1998), se conforma en torno a un conjunto de filmes que tratan principalmente sobre los procedimientos de investigación de diversos agentes de la ley.

Paradójicamente estos títulos, un tanto olvidados dentro de la tradición noir, fueron los preferidos por la crítica del momento, tal como lo describe Foster Hirsch:

los críticos favorecieron al noir cuando se lo ubicaba en el mundo real, en vez del estudio; los thrillers que poseían un estilo documental, como The Naked City (1948) de Jules Dassin y Boomerang! (1947) de Elia Kazan, obtenían las mejores críticas (Hirsch, 1981, p. 10).
A diferencia de ejemplos canónicos como Out of the Past (1947) de Jacques Tourneur o Double indemnity (1944) de Billy Wilder, en estos relatos se retrataba el accionar de las instituciones policiacas y ejercían una clara distinción entre héroes y villanos (policías y criminales respectivamente), desarrollaban sus historias en locaciones con iluminación natural -fuertemente influenciado por el neorrealismo italiano en boga- y utilizaban una voz over muy similar a la "voz de Dios" del documental clásico. ${ }^{3}$ Es decir que, si bien podían compartir ciertos tópicos (como el "culpable equivocado"), los principales elementos que se asocian popularmente con el noir como la fotografía con fuertes contrastes, el relato en primera persona del protagonista y la femme fatale no aparecían en estos filmes, por lo que pueden ser incluidos o no dentro de los estudios sobre el cine negro sin mayores problemas.

La popularidad de esta modalidad en los Estados Unidos no fue muy fructífera, desapareciendo con el cambio de la década; sin embargo, su influencia se sintió en otras latitudes. En este sentido podemos rastrear la existencia de un número de policiales semidocumentales en Argentina durante los primeros años de la década del cincuenta, a partir del estreno en 1949 del filme Apenas un delincuente de Hugo Fregonese, cuyo programa de mano declaraba: "Por primera vez llega a la pantalla argentina la más moderna de las técnicas del cine -la semidocumental". ${ }^{4}$ Tras el éxito de este largometraje se estrenaron en los siguientes años títulos como Captura recomendada (1950), Camino al crimen (1951), Mala gente (1952), dirigidos por Don Napy, Mercado negro (1953) y La telaraña (1954)

3:: La voz over se diferencia de la voz off, más común en el film noir, que pertenece a un personaje de la diégesis. Por el contrario, la voz over no posee cuerpo, pertenece a la instancia enunciativa no diegética y es la encargada de interpretar las imágenes. Mary Ann Doane la describe de la siguiente forma: es "una forma de discurso directo, [que] habla sin mediación al público, pasando por alto a los 'personajes' estableciendo una complicidad entre sí misma y el espectador" (1980, p. 42).

4:: Citado en El heraldo del cinematografista (30 de marzo de 1949). 
de Kurt Land, todos presentados desde las instancias de promoción con el epíteto semidocumental. ${ }^{5}$

Si bien distintos entre sí, estos ejemplos compartían varias características -apelaban a técnicas habitualmente asociadas al documental y la filmación en locaciones naturales- para presentar alabanzas a las fuerzas del orden y dramatizar casos policiales basados en hechos verídicos. En este sentido, la trilogía policial de Napy es el ejemplo más acabado del estilo al contar con la colaboración de distintas instituciones como la Prefectura Nacional Marítima, la Dirección de Aeronáutica Civil, Gendarmería Nacional y, principalmente, la Policía Federal.

A modo de ejemplo, en Captura recomendada se exhibe cómo la policía logra rastrear a los criminales a partir del análisis de una de las balas recuperadas de la escena del crimen. La secuencia de montaje exhibe con detalle algunos de los métodos científicos utilizados por la policía durante las investigaciones criminales e inicia con la imagen de una placa que dice "Dirección de Investigaciones - Gabinete Scopométrico”. Mientras las imágenes muestran a los científicos trabajando, el relato de la voz off explica al espectador:

La bala extraída del cuerpo de la víctima fue examinada. Un perito estableció el calibre y al tipo de arma que corresponde. Las estrías que dejan todas las armas en el plomo de las balas fueron fotografiadas en su desarrollo circular con el Aparato Fotocomparador Sistema Argentino Belaunde. La copia fotográfica obtenida fue comparada con otras similares que estaban archivadas. Esto nos mostró la realidad (Figura 1)

El tenor de esta secuencia y las imágenes que presenta remite necesariamente a los noticieros institucionales del período, que podrían caracterizarse dentro de la modalidad expositiva de Nichols (1997), en tanto presentan una voz que subordina a las imágenes a la información transmitida en la banda sonora. ${ }^{6}$ El estilo de estas escenas, en conjunto con las filmaciones en exteriores, constituyen los aspectos que permitieron en su momento caracterizarlos como semidocumentales,

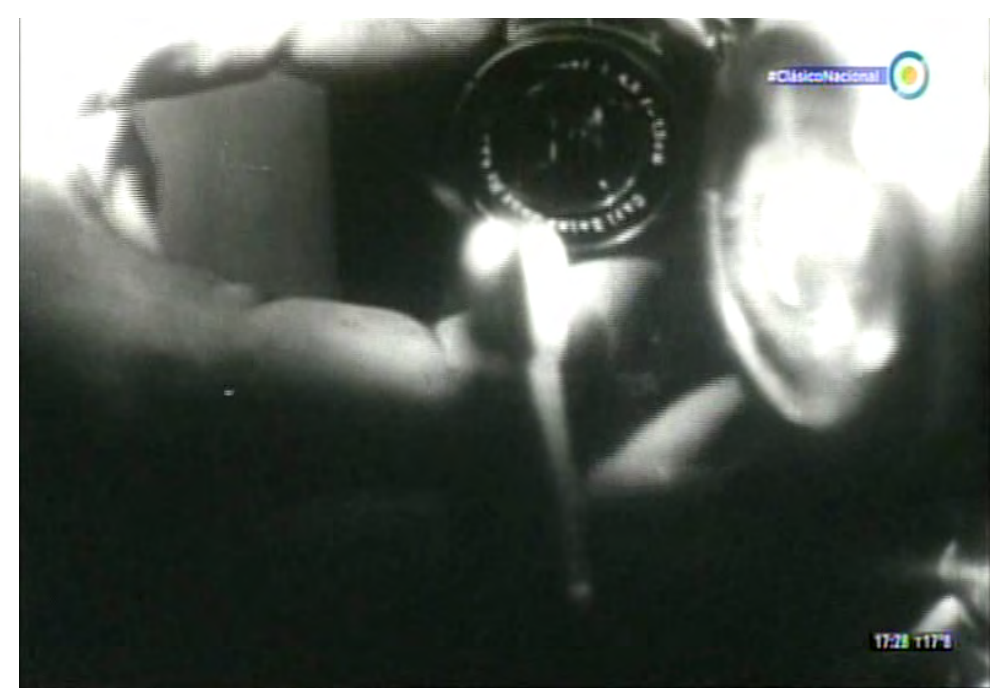

Figura 1. Fotograma de Captura recomendada (1950), de Don Napy.

tanto desde la etapa de producción como en su comercialización y consumo. Sin embargo, esta etiqueta no busca discutir el carácter principalmente ficcional de los filmes, sino que brinda un marco de veracidad y realismo a hechos tomados de la realidad.

Tal como señalamos en el inicio de este trabajo, una de las características del documental contemporáneo es la combinación de elementos del cine de género. En el siguiente apartado nos centraremos en el caso argentino de las apropiaciones del film noir del nuevo siglo, deteniéndonos primero en algunos antecedentes internacionales. Estos filmes no entablan un diálogo con la variante del semidocumental tratada aquí, sino que retoman el imaginario clásico del film noir.

Documentales híbridos en la actualidad: el caso del documental noir

Dentro del terreno documental internacional, el origen de estos cruces suele indicarse con dos filmes específicos: The Thin Blue Line (1988) de Erroll Morris y El diablo nunca duerme (1994) de Lourdes Portillo. En el caso del primero se trata de la investigación sobre el asesinato

5:: A estos ejemplos argentinos se pueden sumar los largometrajes españoles Apartado de correos 1001 (Julio Salvador, 1950) y Brigada criminal (Ignacio F. Iquino, 1950) que comparten múltiples elementos y que permiten pensar un abordaje transnacional del estilo.

6:: Este aspecto no pasaba desapercibido para los espectadores de la época. En el filme de Napy, la voz en off es de Eduardo Rudy, quien también era el encargado de la voz over del noticiero cinematográfico Sucesos argentinos (1938-1972). 
de un policía y la condena a un culpable erróneo; la afiliación con el film noir viene dada por este último tópico, la cuidada fotografía en las múltiples escenas que intentan reconstruir el crimen en cuestión y la música ominosa de Philip Glass. ${ }^{7}$ Uno de los aspectos que le otorgó gran notoriedad al filme de Morris es que concluye comprobando la inocencia del convicto, lo que obligó a la justicia estadounidense a revisar la sentencia.

El segundo de estos filmes fue bautizado por su realizadora como un melodocumystery (Fregoso, 2001, p. 43), debido a sus apropiaciones irónicas tanto del melodrama como del film noir. En El diablo nunca duerme, Portillo intenta resolver el misterio de la muerte de su tío llevando adelante la investigación frente a la cámara. Aquí también se trabaja con imágenes muy estilizadas e iluminaciones oscuras. La adopción de la primera persona es uno de los aspectos que se repetirán en los siguientes exponentes de esta modalidad. Sin embargo, tras revelar múltiples secretos familiares, el final del filme no permite dilucidar el misterio en cuestión.

Un último antecedente clave es Boulevard del crepúsculo (1992) del realizador argentino Edgardo Cozarinsky. En esta producción francesa, Cozarinsky reflexiona sobre el exilio tras su regreso a Buenos Aires. Para esto investiga sobre los destinos de dos actores franceses exiliados y sus últimos días en la Argentina: Reneé Falconetti, la actriz de La pasión de Juana de Arco (1928) de Carl Dreyer, y Robert Le Vigan, protagonista de múltiples clásicos del cine francés. Como señala Pablo Piedras, Cozarinsky encarna el rol de un "detective que aborda las entrevistas y recorre la ciudad silenciosamente. El cuerpo de Cozarinsky es retratado por la cámara casi siempre de espaldas, invitando así al espectador a ocupar un lugar privilegiado en la investigación" (2016, p. 113). ${ }^{8}$

Tras considerar estos ejemplos precedentes pasamos a los dos ejemplos argentinos seleccionados: $E l$ rascacielos latino y Yo no sé qué me han hecho tus ojos. La hibridación en estos documentales se erige principalmente sobre tres pilares: la adopción de la primera persona como eje narrativo, la apropiación de elementos iconográficos y personajes arquetípicos del cine negro y la puesta en escena de una investigación.

En El rascacielos latino y Yo no sé qué me han hecho tus ojos sus realizadores asumen el rol protagónico a la manera de investigadores privados y encaran sus pesquisas a partir de un misterio central: la supuesta relación del Palacio Barolo, un reconocido edificio de la ciudad de Buenos Aires, con La divina comedia de Dante en el primer caso, y la incógnita por el paralelo de la cantante de tango y actriz Ada Falcón desaparecida en la cúspide de su fama en el segundo. Para asumir esta caracterización los directores protagonistas recurren a dos constantes de la construcción del personaje detectivesco cinematográfico: la vestimenta (el típico sobretodo de gabardina utilizado por actores como Humphrey Bogart o Robert Mitchum) y la narración en off(Figuras 2 y 3). No obstante, difieren en los atributos otorgados a los personajes, si bien en ambos se los puede calificar como una primera persona epidérmica siguiendo la clasificación articulada por Pablo Piedras (2014). ${ }^{9}$

7:: En una entrevista en ocasión del estreno, Morris declaró sobre la música: "creo que le da a la película un sentimiento subyacente de inexorabilidad, de inevitabilidad, que es parte del aspecto de cine negro de la historia" (Bates, 1989, p. 17).

8:: El documental de Cozarinsky es un antecedente clave del filme de Wolf y Muñoz tanto temática como formalmente: a la investigación sobre la historia de una actriz se suman las escenas en las que el realizador revisita los antiguos cines de Buenos Aires para encontrarlos transformados en estacionamientos y mercados de pulgas

9:: Piedras propone tres modalidades de la primera persona en el documental "teniendo en cuenta la proximidad entre el objeto del discurso y el sujeto que se lo adjudica" $(2014$, p. 77): autobiográfica, de experiencia y alteridad y epidérmica. 


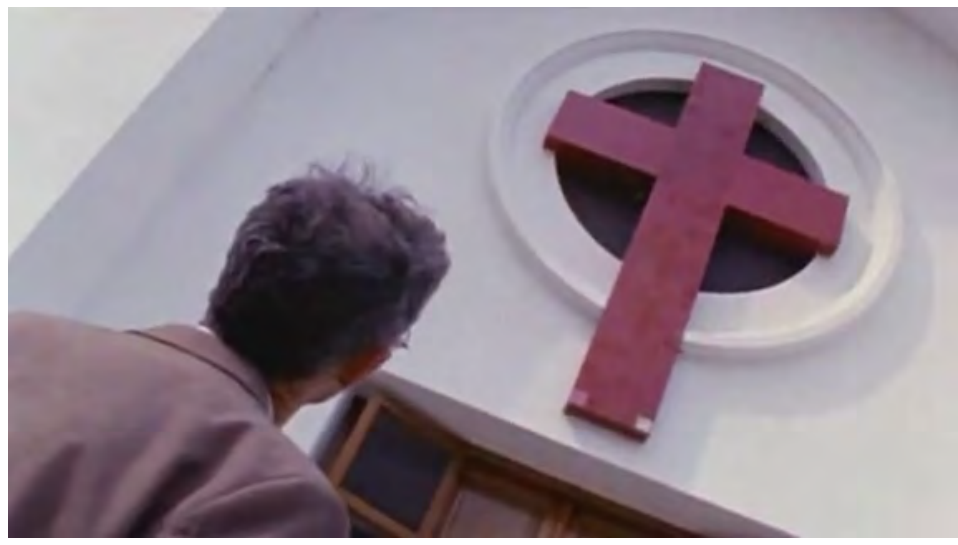

Figura 2. Fotograma de Yo no sé qué me han hecho tus ojos (2003), de Sergio Wolf y Lorena Muñoz

La construcción de los personajes principales es clave, ya que funcionan principalmente como un mecanismo para desarrollar el proceso investigativo. Sumado a esto, podría argumentarse que en ambos ejemplos la adopción estilística pareciera obedecer a la caracterización de la época y las temáticas seleccionadas, ya que tratan aspectos artísticos: el mundo del tango y el cine de la década del treinta, y la arquitectura de principios del siglo XX. Pero como mencionamos previamente, presentan algunas diferencias. El personaje protagónico interpretado por Wolf en Yo no sé qué me han hecho tus ojos intenta establecer una relación personal con su objeto de investigación desde la primera escena del filme, en la que el periodista Aníbal Ford lo introduce al mundo de las cantantes de tango y a la misteriosa historia de Falcón despertando su curiosidad. El relato en off de Wolf explica:

Dejar todo por una convicción, eso es lo que me obsesiona, ir al revés de lo que dice la época, la cruzada espiritual, eso es lo que me une a la historia de Ada. Hay muchas películas posibles sobre las vidas de las cancionistas, pero la de Ada Falcón es la única que me invade, la única que me intriga, la única que vuelve una vez, otra vez, otra vez. Es la historia la que no me deja, no soy yo el que no puedo dejarla.

La obsesión detallada por el protagonista tiene que ver con una mera instancia narrativa y el aspecto lúdico que el documental plantea con su intertexto genérico. A diferencia de esto, El rascacielos latino no intenta justi-

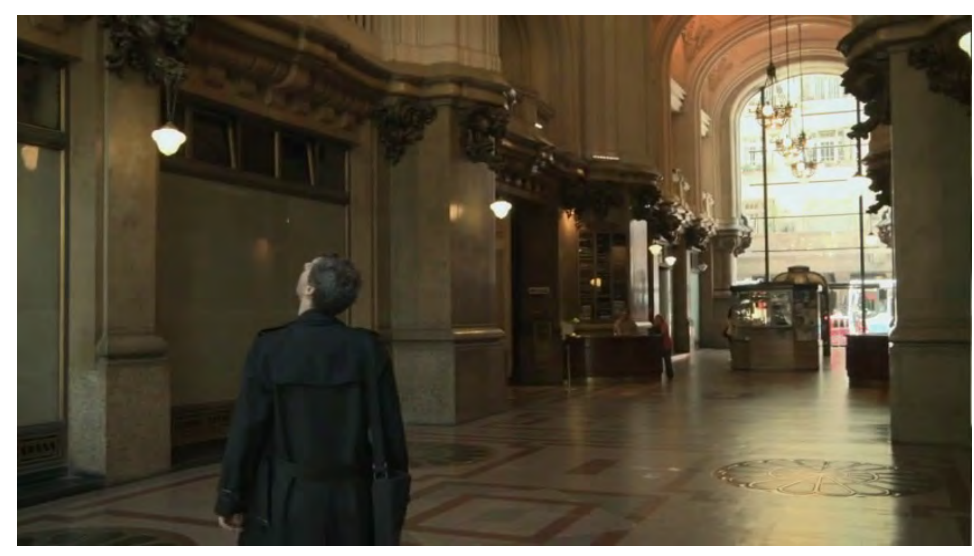

Figura 3. Fotograma de la película El rascacielos latino (2012), de Sebastián Schindel

ficar la intertextualidad desde la narración, sino que se sirve de ella para generar un clima de suspenso y misterio, tal como manifiesta su realizador en entrevistas:

como la historia es de por sí bien misteriosa, para mí se caía de maduro que la estética tenía que ser la del policial negro; una estética contrastada, oscura, atemporal. Y por eso le doy ese clima que creo que la historia ya tiene naturalmente, yo simplemente lo puse en imágenes (Ranzani, 2012).

De esta forma, el realizador no intenta justificar narrativamente los motivos por los cuales su personaje lleva a cabo la investigación, sino que es un mecanismo que permite avanzar e hilar la información expuesta. ${ }^{10}$

El documental de Wolf y Muñoz no solo presenta al detective, sino que recurre a otro personaje arquetípico del cine negro: la femme fatale. El protagonista se refiere en su discurso en off a los ojos de la cantante y el fuerte influjo que ejercen sobre sí mismo (y otros). "Nunca voy a poder ver esos ojos verdes" dice en su relato para caracterizar la obsesión que mueve a su personaje y la investigación. Este tópico remite a uno de los clásicos del film noir, Laura (1944) de Otto Preminger, en el que el protagonista se obsesiona por el retrato del personaje que le otorga su título

10:: En la entrevista a Schindel presentada como extra en la edición en DVD del filme, declara: "necesitaba un hilo conductor, alguien que vaya de un lugar a otro. En un momento pensé en poner a un actor, pero me di cuenta que iba a ser muy complejo". 


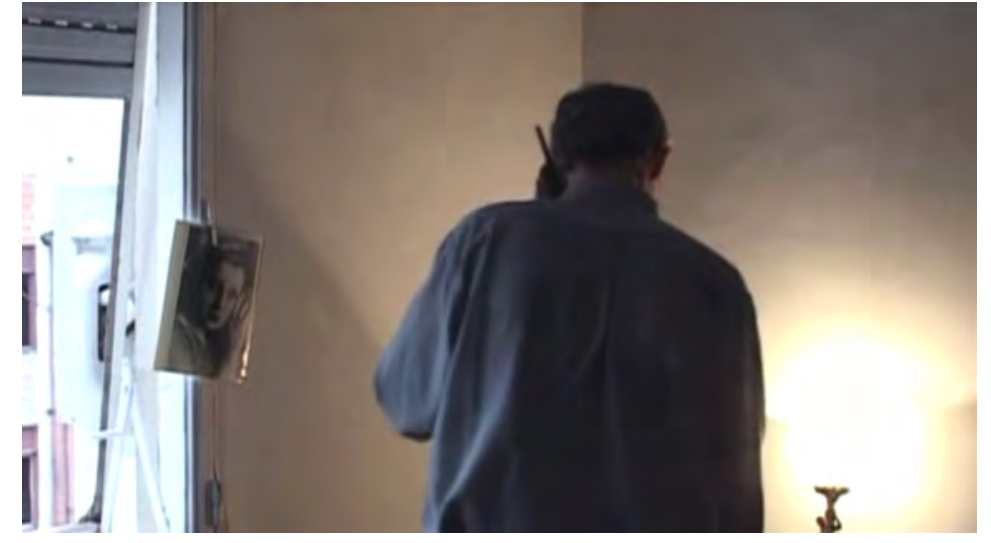

Figura 4. Fotograma de Yo no sé qué me han hecho tus ojos (2003), de Sergio Wolf y Lorena Muñoz

a la cinta y al que Yo no sé qué me han hecho tus ojos remite a partir de cierta construcción visual en las escenas en las que Wolf tiene una foto de la cantante colgada de las cortinas de su habitación a la manera del cuadro del filme de Preminger (Figura 4). ${ }^{11}$

Este tópico nos permite realizar dos inferencias: en primer lugar, que esta apelación al cine negro es exclusivamente lúdica, evidenciando que la cercanía del realizador con su objeto de investigación es ficticia; en segundo lugar, que un arquetipo como personaje puede plantear problemas de corte ético al trabajar con personas reales. El retrato de Falcón como una mujer fatal no le hace justicia a su biografía, tal como la presenta el mismo filme al retratar su vida amorosa, más específicamente su relación con el autor Francisco Canaro que, se sugiere, puede haber sido la razón de su retiro de la vida pública. ${ }^{12}$ La historia de Falcón se asemeja entonces a la de una heroína melodramática y no a la de una femme fatale, pero en su relación con el personaje de Wolf durante la primera sección del filme busca jugar con estos paralelos.

Por su parte, también podemos rastrear en El rascacielos latino ciertos elementos iconográficos que remiten a filmes clásicos del film noir a partir de los múltiples planos detalles de la ornamentación del Barolo. Uno de los aspectos investigados por Schindel se relaciona con una escultura de bronce de un cóndor en la que supuestamente se depositarían los restos de Dante, que despareció en la ciudad de Mar del Plata, y una reproducción de esta. Visual y temáticamente aquí también se podría plantear una relación con el filme The Maltese Falcon (1941) de

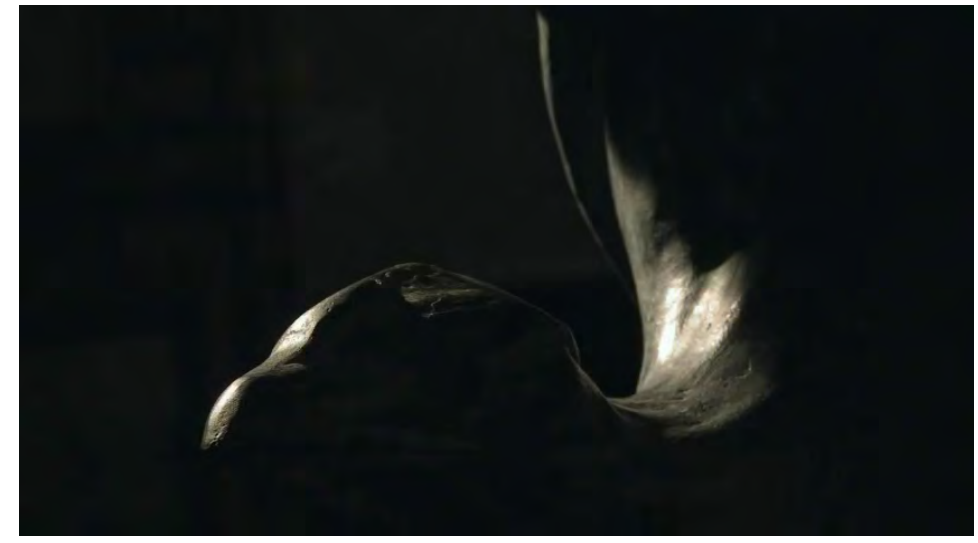

Figura 5. Fotograma de la película El rascacielos latino (2012), de Sebastián Schindel

John Huston, y su famoso final que devela la falsificación de la estatua del título del filme (Figura 5).

El proceso de investigación en ambos filmes es narrado en presente, ya que el espectador comparte con el detective las diversas revelaciones y problemas que van surgiendo. La estructura de ambos documentales sigue lineamientos lógicos: seguimos a los protagonistas a distintos lugares mientras examinan archivos y cada entrevistado aporta información nueva que permite atar cabos para acercarnos a la posible resolución, buscando la participación del espectador.

Uno de los puntos a remarcar es que estas investigaciones suponen una recreación y no un registro sin control, como proponen otras formas del documental, aspecto comprobable en entrevistas a los realizadores. En el caso de Yo no sé qué me han hecho tus ojos, los responsables revelaron que el primer material filmado fue la entrevista a la cantante con la que el filme concluye, y con la posesión de ese material, que podríamos calificar como la sección de "valor documental", procedieron a realizar la primera mitad de la película que propone la investigación de carácter más ficticio.

11:: En los extras de la edición en DVD los realizadores también comentan los parecidos de la historia con el filme de Billy Wilder, Sunset Boulevard (1950), sobre una estrella de cine mudo olvidada por el público.

12:: Justamente uno de los puntos más discutidos en torno a este filme en diversas publicaciones se relaciona con los aspectos éticos y la situación en la que deja a la memoria de la cantante (Alonso, 2003; Piedras, 2014; Lanza, 2016). 
Por último, nos resta referirnos a lo que podríamos denominar el "valor documental" de los filmes: los misterios y sus resoluciones. Schindel abre El rascacielos latino haciendo una serie de preguntas sobre el nexo entre el rascacielos y la obra literaria: “¿Es esta una leyenda urbana sin fundamento? ¿Cuál es el origen de esta mítica relación?”. Para resolver este problema, recurre a una serie de entrevistas que irán abriendo otras líneas de investigación: la arquitectura de Palanti, el edificio mellizo del Barolo (el Palacio Salvo en Uruguay), los restos de Dante, la masonería. Sin embargo, todas las entrevistas presentadas permiten avanzar sin plantear contradicciones ni grandes revelaciones; si el objetivo del filme era establecer las relaciones entre el Barolo y La divina comedia, en ningún momento los entrevistados parecen afirmar que se trata de un mito sin fundamentos. Lo mismo sucede con el misterio final que plantea: ¿el objetivo del Barolo era albergar los restos mortales de Dante? La última entrevista a un Guarda del Templo Interno Masón sugiere que no existen demasiadas razones que sugieran que la respuesta sea negativa.

La narración over concluye: "el verdadero propósito del edificio y quienes sean que están detrás de esta historia permanecen ocultos”, pero, como señala Lior Zylberman, "al quedar confirmado por todos [los entrevistados] el misterio, la leyenda deja de ser tal, no hay contradicciones en el relato, no hay intriga. [...] parecería así que el detective no tenía mucho trabajo ya que todos sus 'informantes' estaban de acuerdo" (2013, p. 197).

En Yo no sé qué me han hecho tus ojos los resultados no llevan a grandes revelaciones, pero sí al descubrimiento del paradero y el registro de los últimos días de la cantante. Durante la primera mitad del filme, en el que se expone el mito de Falcón, se pregunta básicamente el porqué de su desaparición, mientras que en la segunda se expone una entrevista a la cantante en sus últimos días de vida. Los realizadores rastrearon rápidamente a Falcón hasta un pueblo en Córdoba, pero durante la entrevista no lograron conseguir respuestas a los interrogantes planteados previamente, debido a la avanzada edad de la cantante. El filme concluye con Falcón diciendo: "Mi gran amor fue.... No recuerdo". Es productivo recuperar al respecto las palabras de uno de sus realizadores sobre este punto: "en nuestro caso no había verdad, porque había una historia amorosa, la única persona viva que había vivido esa historia era ella, y por lo tanto lo que los otros pudieran decir, opinar, la verdad que no agregaba demasiado" (citado en Feller, 2012, p. 179).

\section{A modo de conclusión}

Uno de los interrogantes iniciales de este artículo giraba alrededor de la problemática de la hibridación documental y ficción como un aspecto exclusivamente contemporáneo; al respecto pudimos constatar, a partir de los intercambios con el cine policial en el caso específico de la filmografía argentina, que esta posee larga data en ambas direcciones. En este texto tratamos dos momentos separados por cinco décadas, por lo que las convenciones y concepciones de lo que implica el discurso documental difieren, al igual que las expectativas de los espectadores.

Las ficciones de los cincuenta entendian por documental la filmación en locaciones, la narración over, ${ }^{13}$ un discurso institucional de propaganda y (en algunos casos) la inspiración en casos reales tomados de archivos oficiales. Frente a un espectador actual, estos filmes se erigen como ficciones con algunos pequeños elementos "disruptivos", por lo que su recepción no es obviamente la misma. En cambio, en los documentales del siglo XXI la concepción misma de la puesta en escena ya no se diferencia sustancialmente de la ficción

13:: Si bien en el filme de Napy, a diferencia de Apenas un delincuente, se trata de la voz del personaje principal, como mencionamos previamente, la voz del actor coincidía con la de los noticieros oficiales. 
genérica, especialmente en la caracterización de los personajes y el relato en off, si bien incluye elementos más asociados al documental como la entrevista y la presentación de archivos fotográficos y fílmicos. Sin embargo, la apelación al estilo noir en estos filmes, a través de personajes y elementos iconográficos, no busca obliterar al discurso documental ni discutir su relación privilegiada con lo real. Es decir que tanto las ficciones de los cincuenta como los documentales del siglo XXI mantienen sus respectivos estatutos, si bien se presentan como híbridos a partir del juego con otras formas.

La dimensión performativa no cumple una función reflexiva, sino que se emplea para construir un armazón narrativo clásico que plantea, en principio, la posibilidad de resolver misterios, aunque sus resoluciones no contengan siempre todas las respuestas. El relato de investigación permite, por otro lado, acceder a una versión (reconstruida) de la investigación documental e incluir elementos y búsquedas que no llevan a respuestas, aspecto en el que se alejan del documental expositivo clásico basado en la estructura de problema-solución y su "discurso de sobriedad".

La utilización de la primera persona no surge entonces de las biografías personales, sino de la cultura a la que estos sujetos pertenecen. En este sentido, resulta necesario remarcar que ambos realizadores han continuado trabajando sobre las temáticas expuestas en estos filmes. Wolf estrenó en 2016 un documental titulado Viviré en tu recuerdo, en el que regresó a Yo no sé qué me han hecho tus ojos para intentar reconstruir los audios perdidos de la primera entrevista a Falcón, mientras que Schindel anunció un documental sobre la figura del Dante, inédito hasta el momento.

Según estudios postcoloniales sobre la hibridez cultural, la imposibilidad de identificar un componente dominante revela la artificialidad de las identidades estáticas y esencialistas (Werbner y Modood, 1997). Los ejemplos documentales abordados en este trabajo no "dejan deliberadamente a su audiencia en un estado de incertidumbre sobre el estado fáctico de lo que están viendo" (Ferrarini, 2020, p. 164), sino que ayudan a crear espectadores que evalúan activamente lo expuesto y reflexionan sobre las formas en las que el cine documental estiliza, simplifica y, en definitiva, narra historias.

Quisiéramos concluir con unas breves reflexiones sobre algunas de las implicancias del cine de género y su diálogo con el documental. La noción misma de género supone formas y estructuras estrictas o un código a seguir, y por este motivo suele considerárselo "conservador". Thomas Sobchack argumenta que "debido a que la película de género no es realista, ya que es tan descaradamente dramática, muchos críticos la han tratado con condescendencia por no ser relevante en relación con los problemas, filosofías y estéticas contemporáneas" (2012, p. 121). Probablemente esto permita comprender mejor el ciclo de semidocumentales de los años cuarenta y cincuenta, los cuales son ciertamente conservadores políticamente (se trata de filmes de propaganda de las fuerzas policiales), pero buscan ampliar los límites del género y, en este sentido, persiguen un objetivo similar al del documental híbrido contemporáneo.

\section{Referencias}

Alonso, M. (2003). Distancias. Kilómetro 111, 5, 176-181.

Arthur, P. (1993). Jargons of Authenticity (Three American Moments). En M. Renov (ed.), Theorizing Documentary (pp. 108134). Londres, Reino Unido: Routledge.

Bajtín, M. (1989). Teoría y estética de la novela. Madrid, España: Taurus.

Bates, P. (1989). Truth Not Guaranteed: An Interview With Errol Morris. Cinéaste, 17(1), 16-17.

Bernini, E. (2012). La indeterminación. En J. La Ferla y S. Reynal (comps.), Territorios audiovisuales (pp. 295-310). Buenos Aires, Argentina: Libraria. 
Broe, D. (2014). Class, Crime and International Film Noir. Londres, Reino Unido: Palgrave McMillan.

Doane, M. A. (1980). The Voice in the Cinema: The Articulation of Body and Space. Cinema/Sound, 60.

Duff, D. (2000). Modern Genre Theory. Londres, Reino Unido: Routledge.

Esquenazi, J.P. (2018). El film noir. Historia y significaciones de un género popular subversivo. Buenos Aires, Argentina: El cuenco de plata.

Feller, E. (2012). Detrás del árbol Investigación para el documental: entrevistas con documentalistas argentinos. Buenos Aires, Argentina: Eudeba.

Ferrarini, L. (2020). Documentary hybrids. En P. Vannini (ed.), The Routledge International Handbook of Ethnographic Film and Video (pp. 164-172). Londres, Reino Unido: Routledge.

Fregoso, R. (2001). The Devil Never Sleeps and Other Films. Texas, TX: University of Texas Press.

Heredero, C. y Santamarina, A. (1998). El cine negro. Maduración y crisis de la escritura clásica. Barcelona, España: Paidós.

Hirsch, F. (1981). The Dark Side of the Screen: Film noir. Nueva York, NY: Da Capo Press.

Lanza, P. (2016). La ética de la representación en el cine documental. Ética y Cine Journal, 6(1), 41-50. Recuperado de https://revistas. unc.edu.ar/index.php/eticaycine/article/view/14860

Naremore, J. (1998). More Than Night: Film Noir in Its Contexts. Berkeley, CA: University of California Press.

Oroz, E., y de Pedro Amatria, G. (2009). La risa oblicua. 0 cuando el humor desvió al documental de su rígido canon. En E. Oroz, y G. de Pedro Amatria (eds.), La risa oblicua. Tangentes, paralelismos e intersecciones entre documental y humor (pp.19-42). Madrid, España: 8 y $1 / 2$ editores.

Place, J. y Peterson, L. (2006). Some visual motifs of Film noir. En A. Silver y J. Ursini (eds.), Film Noir Reader (pp. 65-75). New Jersey, $\mathrm{NJ}$ : Limelight Editions.
Piedras, P. (2014). El cine documental en primera persona. Buenos Aires, Argentina: Paidós.

Piedras, P. (2016). Lo transnacional como expresión de cuestionamientos identitarios en los documentales de Edgardo Cozarinsky y Alberto Yaccelini. En R. Lefere y N. Lie (eds.), Nuevas perspectivas sobre la transnacionalidad del cine hispánico (pp. 104-118). Leiden/ Boston: Brill Rodopi.

Ranzani, 0. (22 de diciembre de 2012). La historia del Barolo es misteriosa. Página 12. Recuperado de http://www.pagina 12. com.ar/diario/suplementos/espectaculos/5-27076-2012-11-21. html

Schrader, P. (2008). Notas sobre el film noir. En J. Palacios y A, Weinrichter (eds.), Gun crazy: serie negra se escribe con $B$ (pp. 307-319). Madrid, España: T\&̈B Editores.

Spicer, A. (2002). Film noir. Edimburgo, Escocia: Longman.

Staiger, J. (2012). Hybrid or Inbred: The Purity Hypothesis and Hollywood Genre History. En B. K. Grant (ed.), Film Genre ReaderIV(pp. 203-217). Austin, TX: University of Texas Press.

Sobchack, T. (2012). Genre Film: A Classical Experience. En B. K. Grant (ed.), Film Genre Reader IV (pp. 121-132). Austin, TX: University of Texas Press.

Werbner, P. P., y Modood, T. (1997). Debating cultural hybridity: Multicultural identities and the politics of anti-racism. Londres, Reino Unido: Zed Books.

Zylberman, L. (2013). El rascacielos latino. Revista Cine Documental, 7, 194-198. Recuperado de: http://revista.cinedocumental. com.ar/el-rascacielos-latino-sebastian-schindel-2012/

\section{Contribución autoral}

a) Concepción y diseño del trabajo; b) Adquisición de datos; c) Análisis e interpretación de datos; d) Redacción del manuscrito; e) revisión crítica del manuscrito.

P. L. ha contribuido en $a, b, c, d$, e. 